\title{
Uma academia toda nossa
}

\section{An arts academy all ours}

\author{
Luciana de Fátima Rocha Pereira de Lyra \\ Atriz, performer, encenadora, diretora, dramaturga e escritora. Docente efetiva do \\ Departamento de Ensino da Arte e Cultura Popular e da Pós-Graduação em Artes da \\ Universidade do Estado do Rio de Janeiro (UERJ), é docente colaboradora e pós-doutora em \\ Artes Cênicas pelo PPGARC da Universidade Federal do Rio Grande do Norte (UFRN). \\ Também é docente colaboradora do PPGT da Universidade do Estado de Santa Catarina \\ (UDESC). Pós-doutora em Antropologia, pela FFLCH/USP, doutora e mestre em Artes Cênicas \\ pelo IA/UNICAMP, coordena seu estúdio de investigação, UNALUNA - PESQUISA E CRIAÇÃO \\ EM ARTE. Sites: www.unaluna.art.br e www.lucianalyra.com.br \\ lucianalyra@gmail.com - https://orcid.org/0000-0001-5440-5482
}

\begin{abstract}
Resumo
Urdido em linhas epistolares, este texto instaura uma reflexão sobre a escrita acadêmica numa perspectiva performática, desvelando a experiência como principal dínamo de textos germinados nas investigações nas artes da cena no Brasil. Do atrito corpo/escritura são engendrados poderosos momentos, alçando as camadas performáticas deste ato $f(r)$ iccional, eminentemente liminar. Utilizando como metáfora uma carta endereçada à escritora feminista Virgínia Woolf e numa pretensão de tomar seu ensaio Um teto todo seu ([1929] 2014) enquanto lúdica inspiração, cogita-se uma academia em artes mergulhada na performance e na poesia.
\end{abstract}

Palavras-chave: Woolf, Virginia, 1882-1941.Escrita e arte. Artes cênicas. Performance (Arte).

\begin{abstract}
Woven into epistolary lines, this text establishes a reflection on academic writing in a performative perspective, revealing the experience as the main dynamo of texts germinated in investigations in the performing arts in Brazil. From the friction between body and writing, powerful moments are generated, raising the performance layers of this preliminary, $f(r)$ ictional act. Using as a metaphor a letter addressed to the feminist writer Virgínia Woolf and in a pretension to take her essay A room of one's own ([1929] 2014), as a playful inspiration, we are considering an arts academy steeped in performance and poetry.
\end{abstract}

Keywords: Woolf, Virginia, 1882-1941. Writing and art. Artes cênicas. Performance art. 
Querida Virgínia,

Você não me conhece, mesmo assim me atrevo a não te chamar senhora, como chamaria minha avó, se ainda estivesse viva como há dias atrás. Você e ela habitaram um tempo mesmo, o mesmo mundo por alguns anos. Quero dizer que resolvi te escrever há pouco e agradeço desde já que possa confiar no que sinceramente coloco em palavras. Na realidade desejo te contar uma breve estória que talvez nos aproxime, mesmo sabendo que hoje você vive em outras possíveis dimensões.

Bem, há quatro meses, antes de se plantar no mundo um estado pandêmico, fui convidada por mulheres pesquisadoras em artes da cena da Universidade do Estado de Santa Catarina (UDESC) para escrever um artigo sobre um certo tipo de escrita que começou a ser experimentada nos últimos anos na seara da academia em artes brasileira, uma escrita destituída de moldes pré-concebidos, mas afeita à arbitrariedade, ao risco de transformar textos acadêmicos em collages de impressões, reflexões e vivências calcadas em processos criativos e na vida viva, fissurando formalismos acadêmicos comuns em nossas universidades.

Preciso lhe confessar que fiquei ao mesmo tempo instigada a aceitar o convite e meditativa sobre como tomar parte de um dossiê organizado por mulheres estudantes de pós-graduação, sendo eu uma professora com espaços bibliográficos já arduamente conquistados. $\mathrm{O}$ fato é que o mergulho nesses pensamentos hamletianos em participar ou não participar, foi fugaz, pois logo empunhei a pena a escrever um texto para o compêndio reunido pelas alunas, pronto em uma semana. Senti que com o artigo poderia amotinar-me com aquelas jovens pesquisadoras, construindo um topos contínuo e, indubitavelmente amoroso, entre ensino e aprendizagem, azeitando as relações mestra-aprendizes com vistas a um só horizonte, a uma mesma luta.

O texto que escrevi na ocasião, de título Escrita acadêmica performática... Escrita F(r)iccional: Pureza e perigo, acabou não fazendo parte da coletânea, mas desdobrou-se no prelo da Urdimento - Revista de Estudos em Artes Cênicas (2020), debatendo o modo como transformamos a experiência artística em escrita e destacando o aspecto liminar deste movimento (TURNER apud DAWSEY, 2005). A saber, o artigo, em vias de publicação, tomou como base pesquisas minhas no Núcleo de Antropologia, Performance e Drama (Napedra/2005-2013); nas experiências com a disciplina por mim ministrada nos programas de pós-graduação em artes da UERJ, 
UDESC e UFRN (2017-2019); e na produção de artigos, dissertações e teses elaboradas com meu grupo de pesquisa MOTIM - Mito, Rito e Cartografias Feministas nas Artes (CNPq).

Percebi que apesar de fiar exemplos da experiência em escrita performática nas universidades a que estou vinculada e onde instaurei experiências nesse campo da escritura em anos de pesquisa; e a despeito de apontar novos desenhos metodológicos, abordando temáticas interditas e epistemologias marginais, o artigo, agora aprovado na Revista Urdimento, não exercitava, ele mesmo, o caráter performático que defendia, era mais um artigo SOBRE a experiência da escrita, do que ele próprio uma EXPERIÊNCIA DE ESCRITURA sob o signo da performance, que em si tem vocação íntima com o que nos acomete.

A aprovação da coletânea nomeada pelas jovens pesquisadoras como Do tema aos modos, reflexões e invenções: pesquisa em artes e as escritas da pesquisa publicada aqui na Revista Da Pesquisa da UDESC, desafiou-me a escrever um novo artigo, que diferente e não melhor ou pior do que o anterior, deveria estar mais conectado com as forças motrizes da vida, aquelas que contaminam o pensamento e que contagiam o exercício de liberdade, um texto comprometido com o exercício existencial, muitas vezes descolado do modelo profissional do pensamento, que trafega na academia tradicional, que transita pelos nossos códigos enquanto professores e estudantes nas universidades de artes no Brasil.

Mas, como imaginamos sempre, escrever não é simples. Especialmente quando buscamos escrituras que nos emancipem, que prezem por nossa autonomia. Por isso busquei, como muitas vezes, na literatura e na dramaturgia, inspiração. Sentei-me às margens de um rio e ponderei ${ }^{1}$ sobre os caminhos e as palavras que deveria tecer. Importante lembrar que, curiosamente, na mesma semana em que a coletânea foi aprovada e resolvi me arvorar em renovado artigo, recebi um presente de minha companheira, um livro-ensaio baseado em dois artigos lidos para a Arts Society, do Newnham College, e para a ODTAA, do Girton College, em outubro de 1928. O livroensaio era seu, Virgínia.

Acredito que, mesmo me considerando feminista há muitos anos e articulando pesquisas sobre feminismos nas artes da cena no contexto brasileiro, não é vergonhoso dizer que não te conhecia a fundo. Talvez travar um diálogo com você de tempos e

\footnotetext{
${ }^{1}$ Em alusão à imagem expressa na abertura do livro Um teto todo seu, de Virgínia Woolf (2014).
} 
espaços aqui neste pequeno artigo possa redimir, em parte, esse deslize, que acredito não ser somente meu. Toda vez que descubro uma mulher e seus feitos no mundo, suas biografias, lembro da historiógrafa francesa Michele Perrot (2007) e seu assombro de perceber uma história "sem as mulheres". Creio que esse espanto de não saber de tantas é comum a muitas de nós, mas o importante é que esse susto se desdobre em peleja por visibilização, pelo exercício da passagem do silêncio à palavra e da mudança de um olhar que, justamente, faz a história na relação incessantemente renovada entre o passado e o presente.

Naturalmente, preciso lhe dizer que eu sabia de sua vida entre os anos de $1882 \mathrm{e}$ 1941, em contexto britânico, também sabia, pelo senso comum, que você teve importante papel não apenas para a literatura, mas também para o Movimento Feminista, em especial na sua primeira ond ${ }^{2}$. Recentemente, em banca de mestrado que pude participar, também soube de sua contribuição para o teatro, ao desenvolver uma obra dramática ${ }^{3}$, embora sem intenção de publicá-la. Então eu sabia que tínhamos estreitas afinidades: a literatura, a dramaturgia, o desejo de novos caminhos de urdidura do mundo. No entanto, com a leitura de seu livro-ensaio e com a ousadia de te ter como inspiração para um artigo, inauguro nossa telúrica e irreversível amizade.

Entendo que tenha uma natureza introvertida, como também eu tinha muito antes do teatro, sei também de sua fragilidade física e emocional, de sua condição social muito privilegiada que poderiam nos afastar, mas sua habilidade com as palavras e desejo de escrever me arrebatam sobremaneira, em especial quando destina às pautas feministas em suas obras. Neste seu livro-ensaio que, confesso, ainda estou na travessia da leitura, você é explícita em sua defesa ao feminismo e numa escrita comprometida com as mulheres escritoras, da qual muitos paralelos podem ser traçados em relação às mulheres pesquisadoras nas artes da cena e como são tecidos seus transbordamentos em monografias, dissertações, teses, ensaios, artigos.

Traduzido no Brasil como Um teto todo seu, de 1929, o primeiro texto seu que tenho o prazer de conhecer, Virgínia, é uma contribuição na escrita de não-ficção, na defesa da emancipação das mulheres. Lendo o livro percebi que como eu, também você foi convidada a realizar um feito. Enquanto eu, era escrever um artigo para um dossiê,

\footnotetext{
${ }^{2}$ Em linhas gerais, convenciona-se como Primeira Onda a organização social e política das mulheres em fins do século XIX e início do século XX, principalmente em torno da reivindicação pelo o direito ao voto. Tal demanda é chamada sufrágio, e suas representantes, sufragistas; é nesse contexto que viveu a escritora britânica.

${ }^{3}$ Com referência ao texto dramático Freshwater: A Comedy, de Virgínia Woolf.
} 
você era ministrar uma palestra com o tema As mulheres e a ficção, na Universidade de Cambridge, em 1928. Nascida você em tempos avós para mim, seu feito tem mérito infinitamente maior do que o meu, e, evidentemente, também é um grande precursor para tantas de nós. Em Um teto todo seu, você faz as perguntas certas, ainda que não tenha sido a primeira mulher a questionar o tratamento oferecido a seu gênero na sociedade, como você mesma lembra que o fez Aphra Bhen (WOOLF, 2014, p. 96).

Logo no princípio de sua obra me encanto com sua capacidade de perceber e legitimar a sua dúvida sobre o tema de sua palestra As mulheres e a ficção. Mais importante ainda é, após circunscrever o tema, você encontrar questões absolutamente coadunadas a serem refletidas pela temática, quais sejam: a vida das mulheres, em si; a ficção que as mulheres escrevem; ou a ficção que é escrita sobre elas, no caso, por autores homens.

Também você continua a me instigar ao te perceber indo à biblioteca da Universidade de Oxbridge, no sentido de fazer uma investigação mais detalhada para sua palestra, são tantos os causos de discriminação contados por você somente nessa jornada até a biblioteca, até mesmo de que só acompanhada uma mulher poderia ali adentrar (WOOLF, 2014, p. 15-17). Seguindo com você reflito sobre a relação das mulheres com a pobreza, você observa que "[...] não se pode pensar direito, amar direito, dormir direito, quando não se jantou direito" (WOOLF, 2014, p. 32). E ainda questiona "Que efeito tem a pobreza sobre a ficção? Quais as condições necessárias para a criação de obras de arte?" (WOOLF, 2014, p. 41). E, parafraseando-te, pergunto eu, quais as condições necessárias para criar e transpor as obras de arte para um campo de reflexão? Quais as universidades e os programas de pesquisa que absorvem e espelham nossas reais experiências?

Você me faz pensar muito, Virgínia, pensar que como na Inglaterra dos anos vinte, do século XX, ainda nos assolam interditos e invisibilidades. Contamos com uma grande contingência de mulheres nas pesquisas em artes no Brasil, em busca de destampar suas experiências na cena e na reflexão sobre a cena, politizando os espaços de um teor de pessoalidade que nada mais são do que microcosmos em ação sem medo no mundo que habitam. Ainda existe obscurecimento de epistemologias feministas e de outros caminhos de escritas estreitamente vinculados a estratégias feministas de criação, como cartas, diários, romances e ensaios, destituídos de uma estrutura androcêntrica enquanto forma e linguagem. 
Pensar numa academia toda nossa é pensar na restauração dessas estratégias de pesquisa e escrita, também provocar agências de fomento à pesquisa que possam financiar um novo pensamento e uma nova forma de expressão de pensamento, validando que as investigações e as suas escrituras rumem aos quintais, aos terreiros, aos ancestrais, aos campos de alteridade, $f(r)$ iccionalizando arte/vida e justificando os discursos autorais. Uma academia que busca no caminho performático legitimar a natureza das experiências, escolhendo o caminho da floresta da performatividade que destampa desafios, imbricando ‘objeto' e ‘sujeito' de pesquisa, implodindo com a ideia de distanciamento do que se olha, do que se estuda, para imprimir um lugar sentido das coisas que se vive. (LYRA, 2020)

Nessa academia que espelha uma escritura livre, a memória pessoal é base para as pesquisas, um dado de construção de autoimagem, de autorreflexão de pesquisadoras e também de pesquisadores afeitos a esse caminho de escrita, etnografando biograficamente de onde brota o interesse da pesquisa e vislumbrando onde insurgem as imagens da pesquisa ao longo de suas vidas.

Seu livro-ensaio, Virgínia, me faz continuar a guerrear para que as mulheres, suas escritas, seus dossiês, suas epistemologias, que podem fazer crescer e refletir toda uma sociedade, não sejam alijadas ou duvidadas, que não sofram com o silenciamento compulsório e a submissão ao discurso patriarcal nos diversos nichos de conhecimento e, invariavelmente, nos espaços acadêmicos.

Com esta carta espero poder contar com você para alargar as estratégias de insurreição contra o patriarcalismo acadêmico. Que possamos nos abrigar sob todos os tetos, inclusive sob uma academia renovada de conceitos e formas de discussão dos mais variados temas, uma academia toda nossa. Que a irmã de Shakespeare, a poeta que você habilmente inventou, possa estar viva em todas nós, em você e em mim, e em muitas outras mulheres que não estão escrevendo ou estudando agora porque estão trabalhando para subsistir ou lavando a louça ou colocando os filhos na cama, em especial, em tempos de pandemia, quando as disparidades se elevam no que tange ao jogo entre gêneros nos redutos exclusivos das casas nas quais estamos todes encerrades.

Profetizemos juntas para uma e para todas: "Dê a ela mais cem anos, [...] dê-lhe um espaço, um teto todo seu e quinhentas libras por ano, deixe que ela diga o que lhe passa na cabeça [...] e ela escreverá um livro melhor algum dia" (WOOLF, 2014, p. 134). 
Deixo-te agora, porque te acenei antes da brevidade desses meus escritos. Claro que tendo você e tantas como guias não posso dar folga à pena e nunca largar as bancadas da universidade, minhas orientações e os palcos do teatro para jorrar o grito. Prometo que vou também conhecer mais suas obras, já tenho outra na vez da leitura: Orlando, que talvez tenha um tanto de minha Joana d'Arc. Seguirei e serei porta-voz de seus conselhos, testemunhando que com você venho aprendendo algo de precioso acerca da essência do processo criador, sua profundidade e eternidade para fazer mundo.

Com carinho infindo pela sua existência antes de mim,

04 de junho de 2020.

Luciana Lyra 


\section{REFERÊNCIAS}

DAWSEY, J. Victor Turner e a Antropologia da Experiência. Cadernos de Campo, São Paulo, v. 13, n. 13, p. 163-176, 30 mar. 2005. DOI: https://doi.org/10.11606/issn.2316-9133.v13i13p163-176. Disponível em: http://www.revistas.usp.br/cadernosdecampo/article/view/50264/54377. Acesso em 04 jun. 2020.

LYRA, L. de F. R. P. de. Escrita acadêmica performática... Escrita F(r)iccional: Pureza e perigo. Urdimento revista de Estudos em Artes Cênicas, Florianópolis, v. 2, n. 38, p. 1-13, ago./set. 2020.

DOI: https://doi.org/10.5965/14145731023820200033. Disponível em: https://www.revistas.udesc.br/index.php/urdimento/article/view/17759/11964. Acesso em: 24 set. 2020.

LYRA, L. de F. R. P. de. Guerreiras e Heroínas em Performance: da Artetnografia à Mitodologia em Artes Cênicas. 2011. Tese (Doutorado em Artes) - Instituto de Artes, Universidade Estadual de Campinas, Campinas, 2011. Disponível em:

http://repositorio.unicamp.br/bitstream/REPOSIP/284426/1/Lyra_LucianadeFati maRochaPereirade_D.pdf Acesso em 04 jun. 2020.

PERROT, M. Minha história de mulheres. São Paulo: Editora Contexto, 2007.

WOOLF, V. Um teto todo seu. São Paulo: Editora Tordesilhas, 2014.

WOOLF, V. Freshwater: a comedy. Florida: Harcourt Inc., 2019. 